\title{
Evaluating Schedule Uncertainty in Unit-Based Repetitive Building Projects
}

\author{
Önder Ökmen ${ }^{1}$
}

\begin{abstract}
Various risk factors affect construction projects. Due to the uncertainties created by risk factors, actual activity durations frequently deviate from the estimated durations in either favorable or adverse direction. For this reason, evaluation of schedule uncertainty is required to make decisions accurately when managing construction projects. In this regard, this paper presents a new computer simulation model - the Repetitive Schedule Risk Analysis Model (RSRAM)— to evaluate unit-based repetitive building project schedules under uncertainty when activity durations and risk factors are correlated. The proposed model utilizes Monte Carlo Simulation and a Critical Path Method based repetitive scheduling procedure. This new procedure concurrently provides the utilization of resources without interruption and the maintenance of network logic through successive units. Furthermore, it enables assigning variable production rates to the activities from one unit to another and any kind of relationship type with or without lag time. Details of the model are described and an example application is presented. The findings show that the model produces realistic results regarding the extent of uncertainty inherent in the schedule.
\end{abstract}

Keywords: Construction management, Repetitive scheduling, Critical Path Method, Risk analysis, Correlation, Simulation models.

\section{INTRODUCTION}

Multi-story building construction, highway construction and pipeline construction projects are some examples of repetitive construction projects. Repetitive construction projects can be categorized in two groups: linear, such as highways, railroads, and pipelines; and nonlinear (or unit-based), such as high-rise building and multiple housing constructions [1]. Such projects require the implementation of a set of identical or similar activities from one unit to another as in the case of multi-story building construction or from one location to another as in the case of highway construction. Scheduling of repetitive construction projects require uninterrupted usage of resources between similar units and enabling timely movement of crews from one unit to the next [2]. Maintenance of the work continuity leads to advantages like the maximization of learning curve effect benefit for each crew, minimization of idle time of each crew and minimization of the off-on movement of crews on a project once work has begun [3].

Bar Chart and Critical Path Method (CPM) scheduling receive criticism in the literature for their inability to maintain work continuity in repetitive projects [4-7]. Furthermore, such scheduling techniques assume the resources as unlimitedly available in the initial development of a schedule and for this reason, requirement to revision occurs later to adjust the schedule to resource limitations [2]. The most convenient method of scheduling and controlling the projects that have repetitive units is the Line of Balance (Linear or Repetitive Scheduling). Unlike Bar Chart and CPM, Repetitive Scheduling provides work continuity between the same activities of successive units in accordance with the resource availability. It leads to smooth and efficient flow of resources and requires less preparation time to produce. This is one of the main advantages of Repetitive Scheduling compared to CPM [8]. Variations of Repetitive Scheduling in the literature include Line of Balance [9], Vertical Production Method [10], Linear Scheduling Method [11], Time Space Scheduling [12], and Time Changes Charts [13].

The most important feature of CPM is its ability to specify critical path(s). Critical path(s) identify the activities which cause delay in project completion time if their completion times extend. For Repetitive Scheduling to be accepted as a valuable tool, it should also be able to determine the critical activities [14]. Scheduling techniques applicable to repetitive projects must be able to provide a synonymous set of critical activities as those calculated by CPM. This ability would provide an analytical or engineering foundation on which a full range of functionality such as float identification, resource and cost allocation, and schedule updating could be built [15]. Determining the critical path in CPM, or controlling activity path in a repetitive schedule, is a crucial aspect. It helps in controlling and updating the original schedule. Resource leveling of a repetitive schedule requires the critical segments as input [16]. Harmelik and Rowings [15] introduced a method - the Linear Scheduling Model - that identifies the controlling activity path through a linear schedule based on the time and distance relationships of activities. The controlling activity path is similar to the critical path of CPM. Harris and Ioannou [17] used a similar approach - the Repetitive Scheduling Method - to identify controlling activities of a repetitive schedule. However, these methods are mainly graphic based techniques. This is a limitation for their practical use. Ammar and Elbeltagi [14] introduced an algorithm for determining the controlling path considering resource continuity. In this algorithm, the production rate of each

${ }^{1} \mathrm{PhD}$, Civil Engineer, Project \& Construction Department, General Directorate of State Hydraulic Works, Ankara, Turkey, onderok@dsi.gov.tr 
activity is compared with that of its successors in order to specify the start-to-start or finish-to-finish relationships between two consecutive units. Duffy et al. [18] proposed a linear scheduling model with varying production rates. Cho et al. [19] introduced a scheduling model for repetitive construction processes for high-rise buildings that allow effective scheduling for repetitive construction processes with flexible job logic. This paper presents a different procedure to apply the CPM to unit-based repetitive building projects. The purpose of developing such a procedure is to utilize it in the repetitive scheduling risk analysis model proposed in this paper. The procedure concurrently provides the utilization of resources without interruption and the maintenance of network logic through successive units. With this procedure, it is possible to represent the activities by variable production rates from one unit to another and to assign any kind of relationship type with lag time. The proposed procedure computes the project completion time, early start/finish times, and late start/finish times through a unit by unit approach.

CPM and Repetitive Scheduling are deterministic methods due to the crisp values used to represent the activity durations and therefore it is not possible to evaluate the effect of uncertainty on construction schedules with these methods. Various risk factors affect the construction projects and it is not possible to estimate the activity durations certainly in advance. This causes CPM and Repetitive Scheduling to misidentify the critical paths and project durations [20]. Construction projects are under the influence of uncertainties related to the risk-factors such as weather conditions, design faults, scope changes, site conditions, and soil properties [21-24]. Furthermore, all of the possible risk-factors in a construction project might be schedule risks because somehow they are related to the schedule directly or indirectly. Due to the uncertainty effect, uncritical activities determined by traditional methods might be critical in practice.

In order to evaluate the uncertainty effect on construction activity networks, researchers have developed nondeterministic scheduling methods such as Program Evaluation and Review Technique (PERT) [25], Probabilistic Network Evaluation Technique (PNET) [26], and Monte Carlo Simulation (MCS) [27]. None of these methods are independent from CPM, rather they can be considered as the improved methods based on CPM. Furthermore, they can be considered as schedule risk analysis methods which can be used in risk management. Schedule risk analysis methods such as PERT, MCS, and PNET are capable of analyzing uncertainty but they are insufficient in identifying the sensitivity of activities individually or the network as a whole to risk-factors. Furthermore, they ignore the correlation effect between activities [28,29]. They approach the uncertainty problem through accepting the activity durations between some estimated boundary values and trying to measure the variance of project completion time. However, in cases where several activities are influenced by the same riskfactor at different levels, their durations are correlated in compliance with these levels. If the activities on a path are correlated, the variability of the path's duration would increase, and depending on this, the project completion date would be highly uncertain due to the uncertainty in path durations [29].

Various schedule risk analysis models can be found in the literature such as Model for Uncertainty Determination (MUD) [30], Factored Simulation [31], Project Duration Forecast (PRODUF) [32], PLATFORM [33], Risk Management Model in CPM Networks [34], Conditional Expected Value Model (CEV) [35], Exact Simulation [36], Networks under Correlated Uncertainty (NETCOR) [29], Judgmental Risk Analysis Process (JRAP) [37], Risk Model of Dependence Among Project Task Durations [38], and Network Evaluation with Correlated Schedule Risk Analysis (CSRAM) [39]. These methods are risk-factor based and they capture the correlation, either directly by using correlation coefficients or indirectly by using qualitative data. While some of them consider both the favorable and adverse effects of risk-factors, some consider only the adverse effect. However, most of the methods that have been developed so far aim at evaluating uncertainty on network schedules. There is a shortage in risk models that analyze uncertainty in the repetitive construction schedules.

This paper presents a new computer simulation model-the Repetitive Schedule Risk Analysis Model (RSRAM) - to evaluate unit-based repetitive building project schedules under uncertainty when activity durations and risk factors are correlated. The proposed model utilizes Monte Carlo Simulation and a Critical Path Method based repetitive scheduling procedure. This new procedure concurrently provides the utilization of resources without interruption and the maintenance of network logic through successive units. Furthermore, it enables assigning variable production rates to the activities from one unit to another and any kind of relationship type with or without lag time. A spreadsheet has been developed on a table processor in order to computerize the RSRAM. Details of the model are described and an example application is presented.

\section{CPM-BASED SCHEDULING PROCUDURE FOR UNIT- BASED REPETITIVE BUILDING PROJECTS}

The main aim of executing CPM is to find out the critical activities and to compute the shortest duration of project completion given the logic and resource availability constraints. In repetitive scheduling, however, not only logic and resource availability but also the continuity of resource usage should be considered. For this reason, the proposed CPM-based repetitive scheduling procedure executes CPM's forward and backward pass calculations through units with maintaining network logic and resource continuity.

The procedure allows the scheduler to represent the repeating activities with variable production rates along successive units. If $\mathrm{ud}_{\mathrm{i}, \mathrm{n}}$ and $\mathrm{r}_{\mathrm{i}, \mathrm{n}}$ denote unit duration and production rate of activity $i$ for a particular unit $n$, respectively, then

$$
r_{i, n}=1 / u d_{i, n}
$$


The procedure requires the following data:

- Precedence relations between activities

- Activity durations along units

- The number of successive units

The following sections describe the procedure on a fictitious activity network containing activities denoted by Act $_{i=1,2 \ldots \mathrm{i} \ldots \mathrm{k}}$

\section{A. Step 1-Forward Pass Calculations}

\section{$1^{\text {st }}$ Activity $\left(\right.$ Act $\left._{1}\right)$}

Set 0 to the Early Start of the Act $_{1}$ for the $1^{\text {st }}$ unit $\left(\mathrm{ES}_{1,1}\right)$. Then, add the unit durations $\left(\mathrm{ud}_{1,1}, \mathrm{ud}_{1,2} \ldots \mathrm{ud}_{1, \mathrm{n}}\right)$ to 0 to find the Early Finish for the $1^{\text {st }}$ unit $\left(\mathrm{EF}_{1,1}\right)$ and Early Start/Early Finish values for the succeeding units $\left(\mathrm{ES}_{1,2} \ldots\right.$ $\left.\mathrm{ES}_{1, \mathrm{n}} ; \mathrm{EF}_{1,2} \ldots \mathrm{EF}_{1, \mathrm{n}}\right)$. This approach will ensure the $\mathrm{Act}_{1}$ to be performed uninterruptedly along units with maintaining the resource continuity.

$$
\begin{aligned}
& \begin{array}{cccc}
\text { Unit 1 } & \text { Unit 2 } & \text {...... } & \text { Unit n } \\
\text { Act } & \text { Un } & &
\end{array}
\end{aligned}
$$

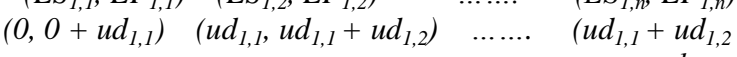

$$
\begin{aligned}
& +\ldots+u d_{1, n-1} \text {, } \\
& u d_{1,1}+u d_{1,2} \\
& +\ldots+u d_{1, n-1} \\
& \left.+u d_{1, n}\right)
\end{aligned}
$$

\section{$\underline{2^{\text {nd }} \text { Activity }\left(\text { Act }_{2}\right)}$}

Act $_{2}$ is the successor of Act $_{1}$.

- $\quad$ Stage -1

$\circ$ If the relationship between $\mathrm{Act}_{1}$ and $\mathrm{Act}_{2}$ is Finish-to-Start (FS) and there is lag time in between $\left(\operatorname{Lg}_{1,2}\right)$, then set Early Start of the Act $_{2}$ for the $1^{\text {st }}$ unit $\left(\mathrm{ES}_{2,1}\right)$ equal to the Early Finish of the $\mathrm{Act}_{1}$ for the $1^{\text {st }}$ unit $\left(\mathrm{EF}_{1,1}\right)$ plus lag time. Then, add the unit durations $\left(\mathrm{ud}_{2,1}, \mathrm{ud}_{2,2} \ldots\right.$ $\mathrm{ud}_{2, \mathrm{n}}$ ) to $\mathrm{ES}_{2,1}$ to find the Early Start/Early Finish values for the succeeding units $\left(\mathrm{ES}_{2,2} \ldots\right.$ $\left.\mathrm{ES}_{2, \mathrm{n}} ; \mathrm{EF}_{2,1} \ldots \mathrm{EF}_{2, \mathrm{n}}\right)$. This approach will ensure the $\mathrm{Act}_{2}$ to be performed uninterruptedly along units with maintaining the resource continuity.

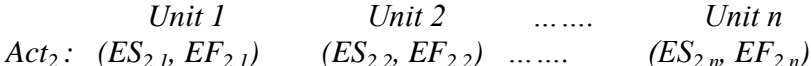

$$
\begin{aligned}
& \left(E F_{1,1}+L g_{1,2}, \quad\left(E F_{1,1}+L g_{1,2} \ldots \ldots . .\left(E F_{1,1}+L g_{l, 2}+u d_{2,1}\right.\right.\right. \\
& E F_{1,1}+L g_{1,2}+u d_{2,1}, E F_{1,1}+\quad+\ldots+u d_{2, n-1}, E F_{1,1}+ \\
& \left.+u d_{2,1}\right) \quad L g_{1,2}+u d_{2,1} \quad L g_{1,2}+u d_{2,1}+\ldots \\
& \left.\left.+u d_{2,2}\right) \quad u d_{2, n-1}+u d_{2, n}\right)
\end{aligned}
$$

- If the relationship between Act $_{1}$ and Act $_{2}$ is Start-to-Start (SS):

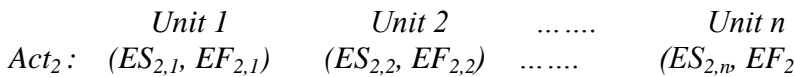

$$
\begin{aligned}
& \begin{array}{cccc}
\left(E S_{2,1}, E F_{2,1}\right) & \left(E S_{2,2}, E F_{2,2}\right) & \ldots \ldots & \left(E S_{2, n}, E F_{2, n}\right) \\
\left(E S_{1,1}+L g_{1,2},\right. & \left(E S_{1,1}+L g_{1,2}+\right. & \ldots \ldots & \left(E S_{1,1}+L g_{1,2}\right.
\end{array} \\
& E S_{1,1}+L g_{1,2} \quad u d_{2,1}, E S_{1,1}+\quad+u d_{2,1}+\ldots+ \\
& \left.+u d_{2,1}\right) \quad L g_{1,2}+u d_{2,1} \quad u d_{2, n-1}, E S_{1,1} \\
& \left.+u d_{2,2}\right)+L g_{1,2}+u d_{2,1} \\
& +\ldots+u d_{2, n-1} \\
& \left.+u d_{2, n}\right)
\end{aligned}
$$

0 If the relationship between $\mathrm{Act}_{1}$ and $\mathrm{Act}_{2}$ is Finish-to-Finish (FF):

$$
\begin{aligned}
& \text { Unit } 1 \quad \text { Unit } 2 \text {....... Unit } n
\end{aligned}
$$

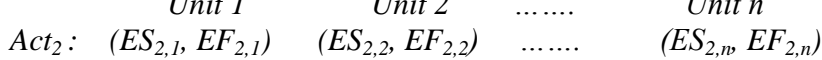

$$
\begin{aligned}
& \left(E F_{1,1}+L g_{1,2} \quad\left(E F_{l, 1}+L g_{1,2}, \quad \ldots \ldots . \quad\left(E F_{l, 1}+L g_{l, 2}\right.\right.\right. \\
& -u d_{2,1}, E F_{1,1} \quad E F_{1,1+} L g_{1,2}+\quad+u d_{2,2}+\ldots+ \\
& \left.+L g_{1,2}\right) \quad u d_{2,2)} \quad u d_{2, n-1}, E F_{1,1} \\
& +L g_{1,2}+u d_{2,2} \\
& +\ldots+u d_{2, n-1} \\
& +u d_{2, n} \text { ) }
\end{aligned}
$$

$\circ$ If the relationship between Act $_{1}$ and Act $_{2}$ is Start-to-Finish (SF):

$$
\text { Unit } 1 \quad \text { Unit } 2 \text {...... Unitn }
$$

$$
\begin{aligned}
& A_{c t_{2}:}:\left(E S_{2,1}, E F_{2,1}\right) \quad\left(E S_{2,2}, E F_{2,2}\right) \quad \cdots \cdots \cdots \quad\left(E S_{2, n}, E F_{2, n}\right) \\
& \left(E S_{1,1}+L g_{1,2} \quad\left(E S_{1,1}+L g_{1,2}, \quad \ldots \ldots . \quad\left(E S_{1,1}+L g_{1,2}\right.\right.\right. \\
& -u d_{2,1}, E S_{1,1} \quad E S_{1,1+} L g_{1,2}+\quad+u d_{2,2}+\ldots+ \\
& \left.+L g_{1,2}\right) \quad u d_{2,2)} \quad u d_{2, n-1}, E S_{1,1} \\
& +L g_{1,2}+u d_{2,2} \\
& +\ldots+u d_{2, n-1} \\
& \left.+u d_{2, n}\right)
\end{aligned}
$$

\section{- $\quad$ Stage -2}

Then, check the logic. The rules are:

For FS case, $E S_{2, n} \geq E F_{1, n}+L g_{1,2}$; for $n: 1,2 \ldots n$

For $S S$ case, $E S_{2, n} \geq E S_{1, n}+L g_{1,2}$; for $n: 1,2 \ldots n$

For $F F$ case, $E F_{2, n} \geq E F_{1, n}+L g_{1,2}$; for $n: 1,2 \ldots n$

For $S F$ case, $E F_{2, n} \geq E S_{1, n}+L g_{1,2}$; for $n: 1,2 \ldots n$

If the corresponding rule is not satisfied, apply the following;

For FS case, $E S_{2, n}^{*}=E S_{2, n}+\operatorname{MAX}\left(E F_{1,1}+L g_{1,2}-E S_{2,1}, \ldots\right.$,

For SS case, $E S_{2, n}^{*}=E S_{2, n}+\operatorname{MAX}\left(E S_{1,1}+L g_{1,2}-E S_{2,1}, \ldots\right.$, $\left.E S_{1, n}+L g_{1,2}-E S_{2, n}\right)$

For FF case, $E F_{2, n}^{*}=E F_{2, n}+M A X\left(E F_{1,1}+L g_{1,2}-E F_{2,1}, \ldots\right.$,

$\begin{aligned} \text { For SF case, } E F_{2, n}^{*}= & \left.E F_{1, n}+L g_{1,2}-E F_{2, n}\right) \\ & M A X\left(E F_{1,1}+L g_{1,2}-E S_{2,1}, \ldots,\right.\end{aligned}$

$\left.\qquad E F_{1, n}+L g_{1,2}-E S_{2, n}\right)$
where n: $1,2, \ldots \mathrm{n}$ and $*$ denotes the new correct value.

\section{$i^{\text {th }}$ Activity $\left(\mathrm{Act}_{\mathrm{i}}\right)$}

An arbitrary activity in the network, Act $_{i}$, may be dependent to more than one predecessor activity $\left(\mathrm{p}_{1}, \mathrm{p}_{2} \ldots\right.$ $\mathrm{p}_{\mathrm{m}}$ ) with different relationships among FS, SS, FF and SF. In this general case, execute the required methods among the FS, SS, FF and SF cases presented through (3) to (6) to obtain Early Start values $\left(\mathrm{ES}_{1}, \mathrm{ES}_{2} \ldots \mathrm{ES}_{\mathrm{m}}\right)$ as many as the predecessors $(\mathrm{m})$ for the activity in question $\left(\mathrm{Act}_{\mathrm{i}}\right)$. Then, in accordance with the CPM's forward pass calculation logic, apply the maximization process on $\mathrm{ES}_{1}, \mathrm{ES}_{2} \ldots \mathrm{ES}_{\mathrm{m}}$ to find the true ES value $\left(E S_{i, 1}\right)$ for the first unit of $A_{c t}$.

$$
E S_{i, 1}=\operatorname{Max}\left(E S_{1,} E S_{2} \ldots E S_{m}\right)
$$

Then, find ES and EF values of the other units of $\mathrm{Act}_{\mathrm{i}}$ $\left(E_{i, 2} \ldots E_{i, n} ; E_{i, 1} \ldots E_{i, n}\right)$. Subsequently, check the logic. The rules are:

$$
\begin{aligned}
& \text { For } F S \text { case, } E S_{i, n} \geq E F_{p, n}+L g_{p, i} \\
& \text { For } S S \text { case, } E S_{i, n} \geq E S_{p, n}+L g_{p, i} \\
& \text { For } F F \text { case, } E S_{i, n}+u d_{i, n} \geq E F_{p, n}+L g_{p, i} \\
& \text { For } S F \text { case, } E S_{i, n}+u d_{i, n} \geq E S_{p, n}+L g_{p, i}
\end{aligned}
$$


If the corresponding rule is not satisfied, apply the following;

For FS case, $E S_{i, n}^{*}=E S_{i, n}+\operatorname{MAX}\left(E F_{p, 1}+L g_{p, i}-E S_{i, 1}\right.$, $\left.\ldots, E F_{p, n}+L g_{p, i}-E S_{i, n}\right)$

For SS case, $E S_{i, n}^{*}=E S_{i, n}+M A X\left(E S_{p, 1}+L g_{p, i}-E S_{i, 1}\right.$, $\left.\ldots, E S_{p, n}+L g_{p, i}-E S_{i, n}\right)$

For FF case, $E F_{i, n}^{*}=E S_{i, n}+u d_{i, n}+M A X\left[E F_{p, l}+L g_{p, i}-\right.$ $\left(E S_{i, 1}+u d_{i, 1}\right), \ldots, E F_{p, n}+L g_{p, i}-$

$$
\left.\left(E S_{i, n}+u d_{i, n}\right)\right]
$$

For SF case, $E F_{i, n}^{*}=E S_{i, n}+u d_{i, n}+M A X\left[E S_{p, l}+\right.$

$$
\begin{aligned}
& L g_{p, i}-\left(E S_{i, 1}+u d_{i, l}\right), \ldots, \\
& E S_{p, n}+L g_{p, i}- \\
& \left.\left(E S_{i, n}+u d_{i, n}\right)\right]
\end{aligned}
$$

where $\mathrm{n}: 1,2, \ldots \mathrm{n} ; \mathrm{p}: \mathrm{p}_{1}, \mathrm{p}_{2} \ldots \mathrm{p}_{\mathrm{m}}$ and $*$ denotes the new correct value.

\section{B. Step 2-Backward Pass Calculations}

Last activity $\left(\mathrm{Act}_{\mathrm{k}}\right)$

Set the Late Finish of the last $\left(\mathrm{k}^{\text {th }}\right)$ Activity for the $\mathrm{n}^{\text {th }}$ unit $\left(\mathrm{LF}_{\mathrm{k}, \mathrm{n}}\right)$ equal to its own Early Finish $\left(\mathrm{EF}_{\mathrm{k}, \mathrm{n}}\right)$. Then, subtract the unit durations $\left(\mathrm{ud}_{\mathrm{k}, 1}, \mathrm{ud}_{\mathrm{k}, 2} \ldots \mathrm{ud}_{\mathrm{k}, \mathrm{n}}\right)$ from $\mathrm{LF}_{\mathrm{k}, \mathrm{n}}$ to find the Late Start for the $\mathrm{n}^{\text {th }}$ unit $\left(\mathrm{LS}_{\mathrm{k}, \mathrm{n}}\right)$ and Early Start/Early Finish values for the predecessor units $\left(\mathrm{LS}_{\mathrm{k}, 1} \ldots\right.$ $\left.\mathrm{LS}_{\mathrm{k}, \mathrm{n}-1} ; \mathrm{LF}_{\mathrm{k}, 1} \ldots \mathrm{LF}_{\mathrm{k}, \mathrm{n}-1}\right)$. This approach will ensure the $\mathrm{Act}_{\mathrm{k}}$ to be performed uninterruptedly along units with maintaining the resource continuity.

$$
\begin{aligned}
& \text { Unit } 1 \quad \text {...... Unit } n-1 \\
& A c t_{k}: \quad\left(L S_{k, 1}, L F_{k, l}\right) \quad \ldots \ldots . .\left(L S_{k, n-l}, L F_{k, n-1}\right) \quad\left(L S_{k, n}, L F_{k, n}\right) \\
& \left(E F_{k, n}-u d_{k, n}-\ldots \ldots\left(E F_{k, n}-u d_{k, n}-\quad\left(E F_{k, n}-u d_{k, n},\right.\right.\right. \\
& \left.u d_{k, n-1}-\ldots-\quad u d_{k, n-1}, E F_{k, n}-\quad=E F_{k, n}\right) \\
& u d_{k, 2}-u d_{k, 1} \text {, } \\
& E F_{k, n}-u d_{k, n}- \\
& u d_{k, n-1}-\ldots- \\
& \left.u d_{k, 2}\right)
\end{aligned}
$$

$\underline{\mathrm{k}-1^{\text {th }} \text { Activity }\left(\operatorname{Act}_{\mathrm{k}-1}\right)}$

$\mathrm{Act}_{\mathrm{k}-1}$ is the predecessor of $\mathrm{Act}_{\mathrm{k}}$.

- $\quad$ Stage -1

- If the relationship is FS and there is lag time in between $\left(\operatorname{Lg}_{\mathrm{k}, \mathrm{k}-1}\right)$, then set the Late Finish of the Act $_{\mathrm{k}-1}$ for the $\mathrm{n}^{\text {th }}$ unit $\left(\mathrm{LF}_{\mathrm{k}-1, \mathrm{n}}\right)$ equal to the Late Start of the Act $_{k}$ for the $n^{\text {th }}$ unit $\left(\mathrm{LS}_{\mathrm{k}, \mathrm{n}}\right)$ minus lag time. Then, apply the unit durations $\left(\mathrm{ud}_{\mathrm{k}-1,1}, \mathrm{ud}_{\mathrm{k}-1,2} \ldots \mathrm{ud}_{\mathrm{k}-1, \mathrm{n}}\right)$ to $\mathrm{LF}_{\mathrm{k}-1, \mathrm{n}}$ to find the Early Start/Early Finish values for the preceding units $\left(\mathrm{LS}_{\mathrm{k}-1,1} \ldots \mathrm{LS}_{\mathrm{k}-1, \mathrm{n}} ; \mathrm{LF}_{\mathrm{k}-}\right.$ $\left.{ }_{1,1} \quad \ldots \mathrm{LF}_{\mathrm{k}-1, \mathrm{n}-1}\right)$. This will provide resource continuity for Act $_{\mathrm{k}-1}$.

$$
\begin{array}{cccc}
\text { Unit } 1 & \ldots \ldots & \multicolumn{1}{c}{\text { Unit } n-1} & \text { Unit } n \\
A c t_{k-1}:\left(L S_{k-1,1}, L F_{k-1,1}\right) & \ldots \ldots . . . & \left(L S_{k-1, n-1}, L F_{k-1, n-1}\right) & \left(L S_{k-1, n}, L F_{k-1, n}\right) \\
\left(E F_{k, n}-u d_{k, n}-\ldots \ldots .\right. & \left(E F_{k, n}-u d_{k, n}-\right. & \left(E F_{k, n}-u d_{k, n}-\right. \\
& L g_{k, k-1}-u d_{k-1, n}- & L g_{k, k-1}-u d_{k-1, n} & L g_{k, k-1}-u d_{k-1, n}, \\
u d_{k-1, n-1}-\ldots- & -u d_{k-1, n-1}, E F_{k, n}- & E F_{k, n}-u d_{k, n}- \\
u d_{k-1,2}-u d_{k-1,1}, & u d_{k, n}-L g_{k, k-1}- & \left.L g_{k, k-1}\right) \\
E F_{k, n}-u d_{k, n}- & \left.u d_{k-1, n}\right) & \\
L g_{k, k-1}-u d_{k-1, n}- & & \\
\left.u d_{k-1, n-1}-\ldots-u d_{k-1,2}\right) & & \\
&
\end{array}
$$

- If the relationship is SS:

$$
\begin{array}{cccc}
\text { Unit } 1 & \ldots \ldots & \multicolumn{1}{c}{\text { Unit n-1 }} & \text { Unit } n \\
A c t_{k-1}:\left(L S_{k-1,1}, L F_{k-1,1}\right) & \ldots \ldots . .\left(L S_{k-1, n-1}, L F_{k-1, n-1}\right) & \left(L S_{k-1, n} L F_{k-1, n}\right) \\
& \left(E F_{k, n}-u d_{k, n}-\ldots \ldots\right. & \left(E F_{k, n}-u d_{k, n}-\right. & \left(E F_{k, n}-u d_{k, n}-\right. \\
& L g_{k, k-1}-u d_{k-1, n-1}- & L g_{k, k-1}-u d_{k-1, n-1}, & L g_{k, k-1}, \\
& \ldots-u d_{k-1,2} & E F_{k, n}- & E F_{k, n}-u d_{k, n}- \\
-u d_{k-1,1}, & & \left.u d_{k, n}-L g_{k, k-1}\right) & \left.L g_{k, k-1}+u d_{k-1, n}\right) \\
& E F_{k, n}-u d_{k, n}- & & \\
L g_{k, k-1}-u d_{k-1, n-1}- & & \\
\left.\ldots-u d_{k-1,2}\right) &
\end{array}
$$

- If the relationship is FF:

$$
\begin{aligned}
& \text { Unit } 1 \quad \ldots \ldots . \quad \text { Unit n-1 Unit n } \\
& A c t_{k-1}:\left(L S_{k-1,1}, L F_{k-1,1}\right) \ldots \ldots .\left(L S_{k-1, n-l}, L F_{k-1, n-l}\right) \quad\left(L S_{k-1, n}, L F_{k-1, n}\right) \\
& \left(E F_{k, n}-u d_{k-1, n}-\ldots \ldots\left(E F_{k, n}-u d_{k-1, n}-\quad\left(E F_{k, n}-u d_{k-1, n}-\right.\right.\right. \\
& L g_{k, k-1}-u d_{k-1, n-1}-\quad L g_{k, k-I^{-}} \quad L g_{k, k-1} \text {, } \\
& \left.\ldots-u d_{k-1,2} \quad-u d_{k-1, n-1}, E F_{k, n}-\quad E F_{k, n}-L g_{k, k-1}\right) \\
& -u d_{k-1,1}, \quad u d_{k-1, n}-L g_{k, k-1}- \\
& E F_{k, n}-u d_{k-1, n}- \\
& L g_{k, k-1}-u d_{k-1, n-1}- \\
& \text {...-ud } \left.d_{k-1,2}\right)
\end{aligned}
$$

$$
\begin{aligned}
& \begin{array}{cccc}
\text { Unit } 1 & \ldots \ldots . & \text { Unit n-1 } & \text { Unit n } \\
\text { Act }_{k-1}:\left(L S_{k-1,1}, L F_{k-1,1}\right) & \ldots \ldots . .\left(L S_{k-1, n-1}, L F_{k-1, n-1}\right) & \left(L S_{k-1, n}, L F_{k-1, n}\right)
\end{array} \\
& \left(E F_{k, n}-\quad \ldots \ldots\left(E F_{k, n}-\quad\left(E F_{k, n}-\right.\right.\right. \\
& L g_{k, k-1}-u d_{k-1, n-1}-\quad L g_{k, k-1}-u d_{k-1, n-1}, \quad L g_{k, k-1} \text {, } \\
& \ldots-u d_{k-1,2} \quad E F_{k, n}-\quad E F_{k, n}-u d_{k-1, n} \\
& \left.\left.-u d_{k-1,1}, \quad L g_{k, k-1}\right) \quad L g_{k, k-1}\right) \\
& E F_{k, n}- \\
& L g_{k, k-1}-u d_{k-1, n-1}- \\
& \left.\ldots-u d_{k-1,2}\right)
\end{aligned}
$$

\section{- $\quad$ Stage -2}

Then, check the logic. The rules are:

For FS case, $L F_{k-1, n} \leq L S_{k, n}-L g_{k, k-1}$

For $S S$ case, $L S_{k-1, n} \leq L S_{k, n}-L g_{k, k-1}$

For FF case, $L F_{k-1, n} \leq L F_{k, n}-L g_{k, k-1}$

For $S F$ case, $L S_{k-1, n} \leq L F_{k, n}-L g_{k, k-1}$

If the corresponding rule is not satisfied, apply the following;

For FS case, $L F^{*}{ }_{k-1, n}=L F_{k-1, n}-M A X\left[L F_{k-1, n}-\left(L S_{k, n}-\right.\right.$

$\begin{aligned} \text { For SS case, } L S_{k-1, n}^{*}= & \left.\left.L g_{k, k-1, n}\right), \ldots, L F_{k-1,1}-\left(L S_{k, 1}-L g_{k, k-1}\right)\right] \\ & =L S_{k-1, n}-\left(L S_{k, n}-L g_{k, k-1}\right),\end{aligned}$ $\left.\ldots, L S_{k-1,1}-\left(L S_{k, 1}-L g_{k, k-1}\right)\right]$

For FF case, $L F^{*}{ }_{k-1, n}=L F_{k-1, n}+M A X\left[L F_{k-1, n}-\left(L F_{k, n}-\right.\right.$

$$
\left.\left.L g_{k, k-1}\right), \ldots, L F_{k-1,1}-\left(L F_{k, 1}-L g_{k, k-1}\right)\right]
$$

For SF case, $L S_{k-1, n}^{*}=L S_{k-1, n}+\operatorname{MAX}\left[L S_{k-1, n}-\left(L F_{k, n}-\right.\right.$

$$
\left.\left.L g_{k, k-1}\right), \ldots, L S_{k-1,1}-\left(L F_{k, 1}-L g_{k, k-1}\right)\right]
$$

where $\mathrm{n}: 1,2, \ldots \mathrm{n}$ and $*$ denotes the new correct value.

\section{$i^{\text {th }}$ Activity (Act $)$}

An arbitrary activity in the network, Act $_{i}$, may be dependent to more than one successor activity $\left(\mathrm{s}_{1}, \mathrm{~s}_{2} \ldots \mathrm{s}_{\mathrm{m}}\right)$ with different relationships among FS, SS, FF and SF. In this general case, execute the required methods among the FS, SS, FF and SF cases presented through (25) to (28) to 
obtain Late Finish values $\left(\mathrm{LF}_{1}, \mathrm{LF}_{2} \ldots \mathrm{LF}_{\mathrm{m}}\right)$ as many as the successors $(\mathrm{m})$ for the activity in question $\left(\mathrm{Act}_{\mathrm{i}}\right)$. Then, in accordance with the CPM's backward pass calculation logic, apply the minimization process on $\mathrm{LF}_{1}, \mathrm{LF}_{2} \ldots \mathrm{LF}_{\mathrm{m}}$ to find the true LF value $\left(\mathrm{LF}_{\mathrm{i}, \mathrm{n}}\right)$ for the last unit of Act $_{\mathrm{i}}$.

$$
L F_{i, n}=\operatorname{Min}\left(L F_{1}, L F_{2} \ldots L F_{m}\right)
$$

Then, find LS and LF values of the other units of $A c t_{i}$ $\left(L_{i, 1} \ldots L_{i, n} ; L_{i, 1} \ldots L_{i, n-1}\right)$. Subsequently, check the logic. The rules are:

For FS case, $L F_{i, n} \leq L S_{s, n}-L g_{s, i}$

For $S S$ case, $L F_{i, n}-u d_{i, n} \leq L S_{s, n}-L g_{s, i}$

For $F F$ case, $L F_{i, n} \leq L F_{s, n}-L g_{s, i}$

For $S F$ case, $L F_{i, n}-u d_{i, n} \leq L F_{s, n}-L g_{s, i}$

If the corresponding rule is not satisfied, apply the following;

$$
\begin{aligned}
\text { For FS case, } L F_{i, n}^{*}= & L F_{i, n}-M A X\left[L F_{i, n}-\left(L S_{s, n}-L g_{s, i}\right), \ldots,\right. \\
& \left.L F_{i, 1}-\left(L S_{s, 1}-L g_{s, i}\right)\right] \\
\text { For } S S \text { case, } L S_{i, n}^{*}= & L F_{i, n}-u d_{i, n}+M A X\left[L F_{i, n}-u d_{i, n}-\right. \\
& \left(L S_{s, n}-L g_{s, i}\right), \ldots, \\
& \left.L F_{i, 1}-u d_{i, 1}-\left(L S_{s, 1}-L g_{s, i}\right)\right] \\
\text { For FF case, } L F_{i, n}^{*}= & L F_{i, n}+M A X\left[L F_{i, n}-\left(L F_{s, n}-L g_{s, i}\right), \ldots,\right. \\
& \left.L F_{i, 1}-\left(L F_{s, 1}-L g_{s, i}\right)\right] \\
\text { For SF case, } L S_{i, n}^{*}= & L F_{i, n}-u d_{i, n}+\left[L F_{i, n}-u d_{i, n}-\right. \\
& \left(L F_{s, n}-L g_{s, i}\right), \ldots, L F_{i, 1}- \\
& \left.u d_{i, 1}-\left(L F_{s, 1}-L g_{s, i}\right)\right]
\end{aligned}
$$

where $\mathrm{n}: 1,2, \ldots \mathrm{n} ; \mathrm{p}: \mathrm{s}_{1}, \mathrm{~s}_{2} \ldots \mathrm{s}_{\mathrm{m}}$ and $*$ denotes the new correct value.

\section{REPETITIVE SCHEDULE RISK ANALYSIS MODEL}

The Repetitive Schedule Risk Analysis Model (RSRAM) is a simulation-based risk analysis model that performs uncertainty evaluation on unit-based repetitive building schedules without neglecting the correlation effect between risk factors and between activities. Correlation is captured indirectly in two directions: one is between activities, and the other between risk factors. Input data complexity or the need for previous data is extremely lowered by utilizing qualitative estimates. For instance, correlation is not realized directly by requesting correlation coefficients (generally not available due to the lack of previous data) from the user; instead, it is captured indirectly by converting qualitative estimates to quantitative values through the iterative computation algorithm of the model. Another attribute of RSRAM is its capability of processing both the adverse and favorable effects of risk factors. For instance, the "weather" risk might occur as worse than expected (adverse) or better than expected (favorable), and RSRAM takes this oppositesided uncertainty effect into consideration for weathersensitive activities. In this regard, the main features of RSRAM can be enumerated as follows:

- Simulation-based uncertainty evaluation algorithm.

- Elicitation of positive correlation indirectly between activity durations.
- Elicitation of positive correlation indirectly between risk factors.

- Simplification of required model input by utilizing qualitative and subjective data.

- Consideration of adverse and favorable effects of risk factors.

- Risk factor sensitivity analysis.

RSRAM is designed as a repetitive construction schedule risk analysis method to be used within a project risk management system. It utilizes the CPM-based scheduling procedure for unit-based repetitive building projects (which is introduced in the previous section) when performing MCS iterations. In every iteration, it simulates the uncertainty in risk-factors (in each iteration, each of the risk-factor may occur as better-than-expected, expected or worse-than-expected) and reflects the adverse and favorable effect of this uncertainty on unit-based activity durations. The distinguishing side of the model is its capability of eliciting positive correlation in between each risk-factor pair and activity pair.

At the end of each RSRAM iteration, different activity durations for each construction unit are produced (and subsequently different durations for the whole project). The determination of whether a risk factor would occur betterthan-expected, expected or wo

rse-than-expected in an iteration is carried out in a random fashion, but without neglecting correlation between risk factors. Moreover, activity unit durations are determined with considering correlation between activities through utilizing qualitative data entered by the user to represent the influence degree of each risk factor on each activity with the qualification terms: very effective, effective or ineffective. Afterwards, these activity unit durations are used in forward-backward calculation of the CPM-based repetitive scheduling procedure. Finally, different duration values for the whole project are produced. When Monte Carlo simulation is completed, all these values are configured in statistical terms and charts such as cumulative probability distributions, standard deviations, means and so on. These resultant data shows the project aspects like probability range of completing duration of the project and sensitivity of the schedule to risk-factors. The manager can use these data in decision-making, schedule controlling, risk response strategy development, resource allocation and etc. For instance, by recognizing which riskfactor is more effective on the schedule, a manager would be aware of what to control during the execution of the activities. The process diagram that shows how RSRAM operates is illustrated in Figure I.

Conventional procedures such as Repetitive Scheduling Method, CPM (which produces deterministic results without giving any information about risk sensitivity) and Simulation Based CPM (which produces stochastic results without eliciting correlation effect between schedule variables) are unrealistic techniques for representing the uncertain construction project environments. If more than one activity is candidate to be influenced by the same risk-factors, the duration of these activities would be correlated. For example, if the duration 
of one of the two correlated activities occurred as morethan-expected due to risk-factors during an iteration, the duration of the other activity should also be taken as morethan-expected during this iteration. Unless such correlation effects are not incorporated into a scheduling model, unrealistic results will have been obtained. Therefore, the main argument and target of RSRAM is to model the uncertain conditions of unit-based repetitive building construction more realistically from the scheduling point of view.

The next section presents detailed information about the operation of RSRAM process, under different headings that disclose its different features.

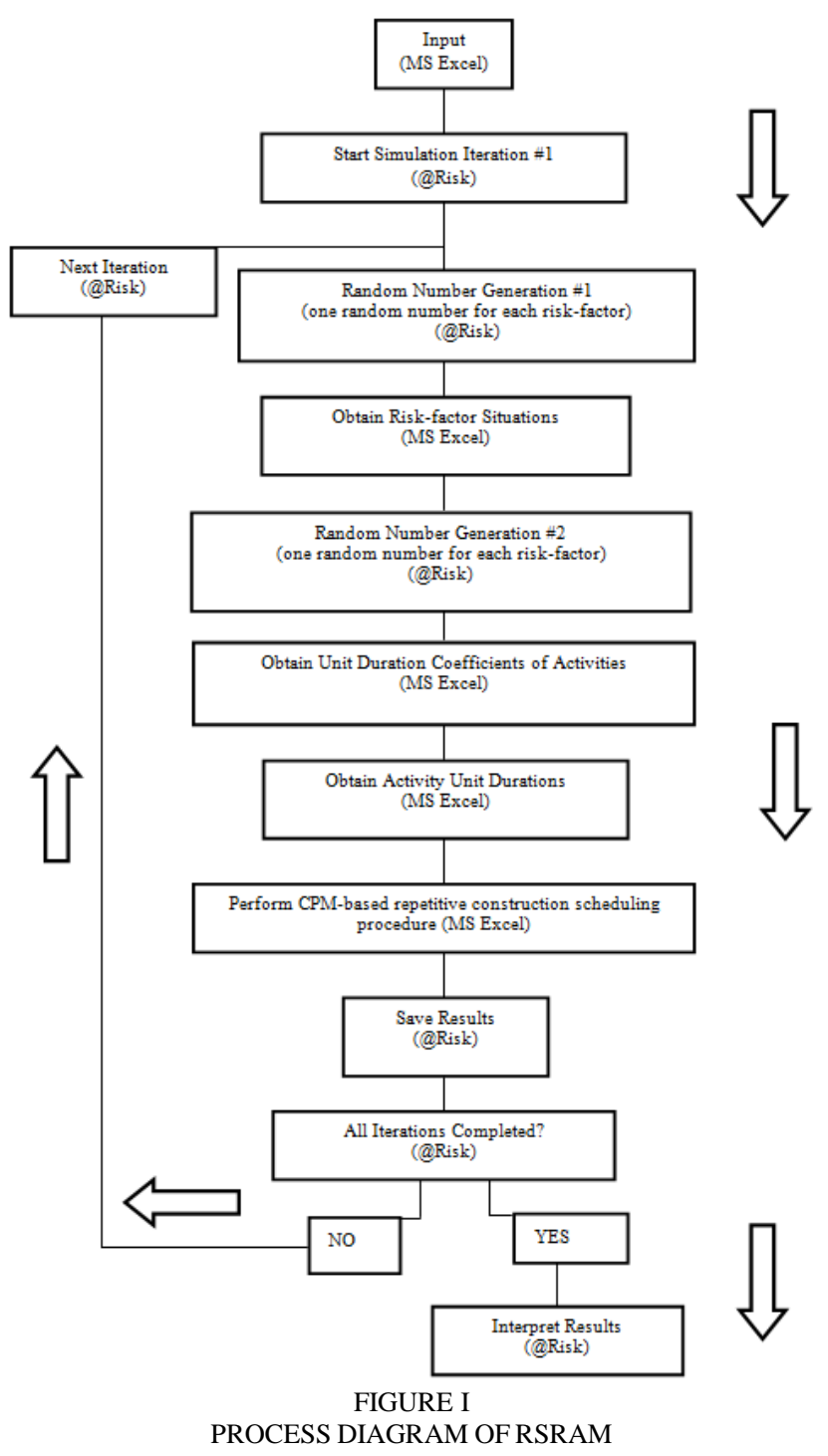

\section{A. Simplified Input Data}

RSRAM is designed such that, required input data is extremely easy to obtain. In other words, data that should be entered into RSRAM are mainly subjective, qualitative, depending on past experience and therefore flexible for adaptation to specific conditions. The input data that RSRAM requires are enumerated and described below:
- Network data: Work breakdown structure for a single unit, predecessor relationships between activities (finish-to start, start-to-start, start-tofinish or finish- to-finish), lag/lead times; which all are the data already needed for a simple CPM application.

- Minimum-most likely-maximum activity unit durations: Nothing more than PERT needs. No probability distributions, no dependence on previous sample data for statistical analysis as in the case of Simulation Based CPM.

- Most important risk-factors that are expected to affect the schedule: It is possible to obtain this information from the risk identification stage of a general risk management system execution.

- Activity Risk-factor influence degrees: these are the qualitative terms; very effective, effective or ineffective. The user selects the appropriate qualification for each "activity $\sim$ risk-factor" pair. This data shows the relative degree of how much a particular risk-factor creates uncertainty on a particular activity's duration.

- Risk-factor situation probability boundaries: Riskfactors may occur as better-than-expected, expected or worse-than-expected in real life. In each situation, they create favorable, neutral or adverse uncertainty on activity unit durations, respectively. RSRAM needs to know the probability boundaries of risk-factors' different situations to decide which situation will occur for a particular simulation step; so that the total effect of risk-factors on activity unit durations are determined by the utilization of "activity $\sim$ riskfactor influence degrees" in conjunction with the risk factor situations. "Risk-factor situation probability boundaries" are judgmentally determined by the help of past experience and entered as numerical values between 0 and 1 . For instance, when the user estimates that laborproductivity risk is very probable to occur as worse-than-expected, less probable to occur as expected and least probable to occur as betterthan-expected, he/she may enter $0.10-0.40-$ 1.00 values respectively to represent better-thanexpected, expected and worse-than-expected risk factor situation probability boundaries of this risk factor. Of course, these values are judgmental and their extents may change from user to user.

- Correlation between risk-factors: RSRAM requires the information about which risk-factors are correlated. For instance, if the user estimates that as weather goes worse-than-expected, labor productivity will be worse-than-expected or as weather becomes better-than-expected, labor productivity will be worse-than-expected, one may enter the information in the model that these two risk-factors are correlated. Eventually, 
RSRAM's computation algorithm behaves accordingly.

- Simulation properties: The user should also enter characteristic preferences for a Monte Carlo simulation. The main preferences are iteration number and seed value. Generally, an iteration number equal or greater than 1000 is sufficient. Selection of the same seed value provides the selection of the same random variables for different simulations and is useful for comparison of the results of different simulations under the same randomly generated conditions.

Input-output chain of the model is illustrated briefly in Figure II.

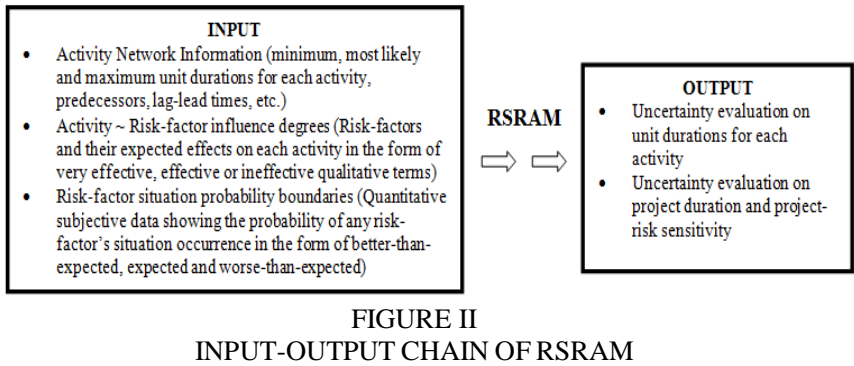

\section{B. Elicitation of Correlation between Activity Unit Durations}

RSRAM is eligible for eliciting correlation between activity unit durations indirectly. The user is not required to enter directly the correlation coefficients. Instead, correlation is supplied by activity risk-factor influence degrees entered by the user in the form of very effectiveeffective-ineffective qualitative terms. Correlation between activity unit durations is captured by entering the same or close qualitative estimates (very effective-very effective or very effective-effective) for any two activities thought to be sensitive to a particular risk-factor.

For the sake of comprehension of RSRAM's correlation capturing mechanism, consider the threeactivity path shown in Figure III.

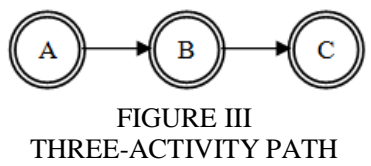

Other required data is given in Table I. All risk-factors are assumed to be uncorrelated for the sake of simplicity. As shown in Table I, the first two activities are strongly correlated when risk-factor- 1 is considered because the risk-factor $\sim$ activity influence degrees of both activities are qualified by the very effective term. When risk-factor-2 is considered, these two activities are assumed to be correlated again by the very effective - effective pair, but weaker with respect to risk-factor-1. When risk factor 5 is considered, they are not correlated because risk-factor-5 is not effective on Activity B. Ineffective term is used for risk-factor-5's influence on Activity B. Now, consider iteration \#1. Assume that RSRAM produced the random numbers $0.82,0.89,0.19,0.75,0.79,0.04,0.15,0.24,0.91$ and 0.64 for risk-factor-i (i: $1,2, \ldots, 10)$, respectively, in order to determine the risk-factor situations for this particular iteration. RSRAM conducts this operation as follows (Refer to Table I):

- iteration \#1-rnd.no.\#1=0.82>0.60 $\Rightarrow$ worse-than-expected (risk-factor-1)

- iteration \#1-rnd.no.\# 2=0.89>0.60 $\Rightarrow$ worse-than-expected (risk-factor-2)

- iteration \#1-rnd.no.\# 3=0.19<0 $0.23<0.50 \Rightarrow$ expected (risk-factor-3)

- iteration \#1-rnd.no.\# 4=0.75 > $0.70 \Rightarrow$ worse-than-expected (risk-factor-4)

- iteration \#1-rnd.no.\# 5=0.79>0.70 $\Rightarrow$ worse-than-expected (risk-factor-5)

- iteration \#1-rnd.no.\# 6=0.04 $<0.30 \Rightarrow$ better-than-expected (risk-factor-6)

- iteration \#1-rnd.no.\# 7=0.15 $<0.30 \Rightarrow$ better-than-expected (risk-factor-7)

- iteration \#1-rnd.no.\# 8=0.20<0.24<0.60 $\Rightarrow$ expected (risk-factor-8)

- iteration \#1-rnd.no.\# 9=0.91 >0.70 $\Rightarrow$ worse-than-expected (risk-factor-9)

- iteration \#1-rnd.no.\#10=0.64 > $0.60 \Rightarrow$ worse-than-expected (risk-factor-10)

After the risk-factor situations are determined, RSRAM generates second random numbers (equal to the number of risk-factors) to compute the activity unit durations to be used in conduction of the CPM-based repetitive construction scheduling procedure in iteration\#1. Assume that second random numbers generated are 0.52 , $0.47,0.31,0.92,0.81,0.99,0.87,0.27,0.61$ and 0.98 for risk-factor-i (i: i: 1, 2, ., 10), respectively. Now, consider the Activity A. The duration of this activity for Unit 1 is computed as follows:

1. If activity duration coefficient of Activity $A>0 \Rightarrow$ Activity duration for Unit $1=[$ most likely duration + (maximum duration - most likely duration) $\times$ activity duration coefficient $]$

2. If activity duration coefficient of Activity $A<0 \Rightarrow$ Activity duration for Unit $1=$ [most likely duration $+($ most likely duration - minimum duration) $\times$ activity duration coefficient]

where,

10

Activity Duration Coefficient of Activity A $=\sum\left[(\text { random no. })_{i} \times{ }_{i}\right.$ $=1$ (activity/riskfactor influence degree

such that, value $_{i}$ ]

If (risk-factor situation $)_{i}$ is better-than-expected $\Rightarrow$ (activity/risk-factor influence degree value $)_{i}<0$

If (risk-factor situation $)_{i}$ is worse-than-expected $\Rightarrow$ (activity/risk-factor influence degree value $)_{i}>0$ 
If $(\text { risk-factor situation })_{i}$ is expected $\Rightarrow($ Activity/risk-factor influence degree value $)_{i}=$ 0

where,

If (activity/risk-factor influence degree $)_{i}$ is "very effective" $\Rightarrow$ $(\text { activity/risk-factor influence degree value })_{i}=$ If (activity/risk-factor influence degree $)_{i}$ is "effective" $\Rightarrow$ $(\text { activity/risk-factor influence degree value })_{i}=$ $1 \times 1 /[(2 \times$ number of "very effective" terms assigned to Activity A $)+(1 \times$ number of "effective" terms assigned to Activity A)]
$2 \times 1 /[(2 \times$ number of "very effective" terms assigned to Activity A $)+(1 \times$ number of "effective" terms assigned to Activity A)]

If (activity/risk-factor influence degree $)_{i}$ is "ineffective" $\Rightarrow$ $(\text { activity/risk-factor influence degree value })_{i}=0$

TABLE I

DATA OF THREE-ACTIVITY PATH

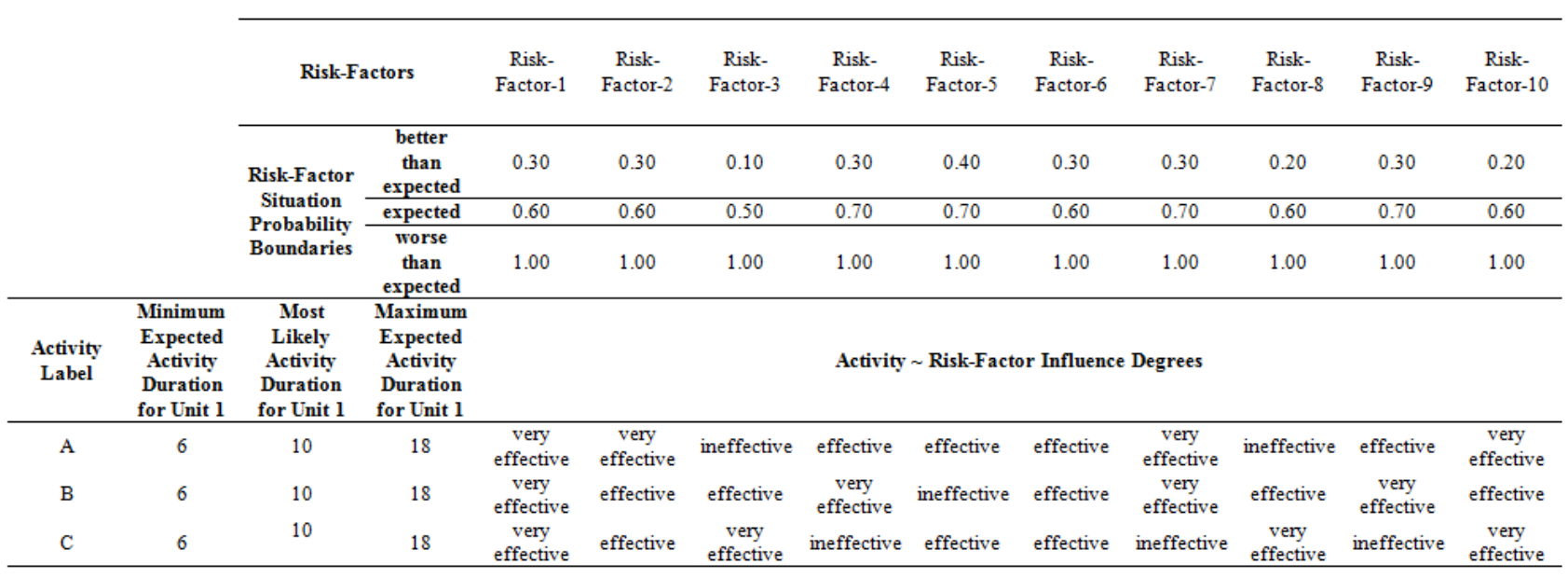

RSRAM assumes that the influence of "very effective" qualification on uncertainty is twice the influence of "effective" qualification. For this reason, the model distributes the influence of uncertainty in 2 to 1 proportion between "very effective" and "effective" terms, respectively.

By the computation based on influence degrees, qualitative terms are converted to numerical values to be used in activity duration calculation in iteration \#1 and in other iterations as well. Notice that the same random numbers are used in the computation of all the activities' durations in a particular iteration. Following the above procedure, Activity A's duration in iteration\#1 is computed as follows:

Activity/risk-factor influence degree value for "very effective" $=2 \times 1 /[(2 \times 4)+(1 \times 4)]=1 / 6$

Activity/risk-factor influence degree value for "effective" = $1 \times 1 /[(2 \times 4)+(1 \times 4)]=1 / 12$

Activity Duration Coefficient of Activity A =

$$
\begin{aligned}
& 1 \times(0.52 \times 1 / 6)+1 \times(0.47 \times 1 / 6)+0 \times(0.31 \times 0)+ \\
& 1 \times(0.92 \times 1 / 12)+1 \times(0.81 \times 1 / 12)+(-1) \times \\
& (0.99 \times 1 / 12)+ \\
& (-1) \times(0.87 \times 1 / 6)+0 \times(0.27 \times 0)+ \\
& 1 \times(0.61 \times 1 / 12)+1 \times(0.98 \times 1 / 6)
\end{aligned}
$$$$
=0.296>0 \Rightarrow
$$

Activity duration of Activity A for Unit $1=$ [most likely duration + (maximum duration - most likely duration) $\mathrm{x}$ activity duration coefficient]

Activity duration of Activity A for Unit $1=[10+(18-10)$

$$
\mathrm{x} 0.296]
$$$$
=12.37 \text { days }
$$

RSRAM computes the durations of other activities during the simulation iterations in the same manner. It can be recognized that if the duration coefficient of an activity was found less than zero in a particular iteration, the activity duration would be computed between most likely and minimum activity durations. In the example above, since the activity duration coefficient of activity A was computed greater than zero, the activity duration of Activity A for Unit 1 has been computed between most likely and maximum activity durations.

\section{Elicitation of Correlation between Risk-Factors}

Another distinguishing feature of RSRAM is its capability of modeling correlation between risk factors. The indirect elicitation method is followed just as it was for the correlation elicitation between activities. In other words, correlation coefficients between risk factors are not 
required. Risk factors are not represented with probability distributions in RSRAM; accordingly, correlation coefficient values are not necessary, but instead, they are represented by risk-factor situation probability boundaries. These input data are requested from the user in quantitative terms between 0 and 1, based on engineering judgment, experience and previous data.

RSRAM provides the correlation between risk factors through two steps: first, it equates the risk factor situation probability boundaries of the risk factors that the user entered in the model as correlated; second, it generates the same random numbers for the correlated risk-factors to determine their risk-factor situations and to compute the durations of the activities that are affected from them. The activity duration computation procedure is the same as shown in the previous section.

\section{Simulation Based Uncertainty Evaluation Algorithm}

RSRAM evaluates the uncertainty in a repetitive construction schedule by executing the Monte Carlo simulation technique. Scheduling is a complex problem and a model produced for analyzing a schedule cannot be solved analytically. Simulation techniques are utilizable in such cases. Any iteration represents a different story for the whole project in different random conditions created in accordance with the input data. The CPM-based repetitive scheduling procedure produces different project durations and controlling (critical) paths in any iteration. All these values are saved by RSRAM and the uncertainty and risksensitivity is measured by integrating these data into statistical charts or values like probability distributions, means or variances.

The distinguishing schedule evaluation feature of RSRAM lies in the way it computes the activity durations with incorporating a positive correlation between activity durations and between risk factors indirectly. RSRAM's simulation and risk-based correlation elicitation algorithm produces more realistic results for managing schedule uncertainty. It simulates a schedule several times and helps the engineer to observe how the real system might behave in reality.

Random numbers are utilized in RSRAM. The probability of getting a value between 0 and 1 during a random number generation is equal when uniform probability distribution is used. The equal chance of getting any value between 0 and 1 represent the real system more realistically. For example, consider two risk factors that are not correlated. Since they are uncorrelated, the random numbers generated for determining their situations are produced independently in any iteration. However, if these two activities were introduced as correlated to the model, the same random numbers would be generated for determining their situations. In a particular iteration, if these two risk-factors are uncorrelated, their situation might occur as better than expected - better than expected, better than expected - worse than expected, worse than expected - better than expected or worse than expected worse than expected, respectively. In real life, this is also the case; for instance, the soil conditions or weather situation may occur randomly. Random numbers generated through uniform probability distribution by RSRAM are utilized for modeling a kind of randomness like that experienced in real life.

RSRAM determines the risk-factor situations during iterations by selecting the situation of a risk-factor through a comparison of the randomly generated numbers against the "risk factor situation probability boundaries" entered by the user. For instance, if it is expected that soil conditions will occur worse than expected with a dominant probability, the risk factor situation probability boundaries for soil conditions are entered accordingly and so the probability of getting worse than expected situation for soil conditions is increased in any iteration, despite the chance of getting any value between 0 and 1 that is used in the determination of a risk factor situation being equal.

\section{E. Activity-based and Project-based Risk-factor Sensitivity Analysis}

RSRAM provides useful information to a manager or decision-maker about the uncertainty inherent in a building construction project. The information provided is two sided: activity and project-based. Main provisions are the variation in unit-based criticality of any activity, the sensitivity of any activity to any risk factor, the variation in total project duration and the sensitivity of the whole project to any risk factor. Such information is invaluable for a manager to know in advance the sensitivity of the schedule variables to various risk factors, develop risk response strategies and take precautions for the success of the project. For instance, if the manager is aware that a particular activity is highly sensitive to a particular riskfactor and this activity contains units that are candidate to become on controlling path with a high probability, then it is possible to develop strategies for lowering the effect of that particular risk factor on the units in question. If it is not possible to know this in advance, the risk of a schedule overrun will increase due to the risk of an increase in that activity's duration. RSRAM helps the manager to recognize how and what to manage in a repetitive schedule. In some way, the manager becomes aware of the extent of uncertainty and its effect on the schedule.

\section{AN EXAMPLE APPLICATION}

In this section, RSRAM is evaluated on a project that includes the construction of four warehouse units. RSRAM input data for the project are given in Table II. Ten risk factors are assumed to influence the schedule, and risk factors 1 and 2, and 5 and 9 are assumed to correlate. Two different analyses are conducted as follows:

- Application of the CPM-based repetitive scheduling procedure, simulated CPM-based repetitive scheduling procedure (conducted by utilizing Monte Carlo simulation) and RSRAM to the project, and comparison of the results. 
- Conducting project-risk sensitivity analysis through RSRAM to observe which risk factors are more effective on the schedule.

The major aim of this section is to show the applicability of RSRAM to a repetitive multi-unit building project and to show its capability of performing risk analysis on the schedule. The benefit of the results of the project-risk sensitivity analysis from the managerial point of view is also mentioned through some discussions. MS Excel and @Risk software programs have been used for the model's execution. First of all, forward-backward pass calculations of the CPM-based repetitive scheduling procedure has been achieved by using MS Excel formulas on an MS Excel spreadsheet. This step is important because RSRAM is based on the CPM-based repetitive scheduling procedure, as previously emphasized. Afterwards, RSRAM has been modeled on the same spreadsheet through designing the input cells first and setting up the model's algorithm with MS Excel formulas second. The last step of the model's execution on the multi-unit case project schedule has been conducting Monte Carlo simulation by using the commands of @ Risk software program. In Figure I, this procedure has been clarified by noting the utilized software next to each item of the model's process diagram. @ Risk is indeed an add-in of MS Excel, to which it adds risk analysis and simulation capability. After any simulation, it reports the statistical results automatically in a regulated fashion. In this regard, the results of the RSRAM execution that are introduced through the next subsections have been extracted from @ Risk's reports and summarized. It should also be mentioned that the CPM-based repetitive scheduling procedure has been carried out by utilizing MS Excel formulas, and the simulated CPM-based repetitive scheduling procedure has been performed by using both MS Excel formulas and @Risk.

A. Applications of CPM-based Repetitive Scheduling Procedure, Simulated CPM-based Repetitive Scheduling Procedure and RSRAM

RSRAM has been applied to the project data given in Tables II and III. The CPM-based repetitive scheduling procedure and the simulated CPM-based repetitive scheduling procedure have been applied to the project data given in Table II. The most likely durations given in Table II have been used in the CPM-based repetitive scheduling procedure execution. The statistical results and the project duration cumulative probability distributions produced by the simulated CPM-based repetitive scheduling procedure and RSRAM are presented in Table IV and Figure IV, respectively. In the application of simulated CPM-based repetitive scheduling procedure, the activity unit durations are assumed to follow triangle probability distributions.
1000 iterations have been conducted in all simulations. The results reveal that RSRAM produces a larger maximum-minimum project duration interval and greater standard deviation with respect to the simulated CPM-based repetitive scheduling procedure. In other words, the uncertainty effect is larger than the simulated CPM-based repetitive scheduling procedure supposes. This is also clear in Figure IV, where the cumulative probability distribution produced by RSRAM is wider than the other distribution. The uncertainty is obviously caused by the risk factors and the correlation effect between activities and between risk factors. When the correlation coefficients captured by RSRAM and the simulated CPM-based repetitive scheduling procedure in Table IV are compared, the correlation effect can be observed more clearly. Except from RSRAM, the CPM-based repetitive scheduling procedure and the simulated CPM-based repetitive scheduling procedure have no capability of capturing correlation and exploring the actual uncertainty level.

Project completion time has been found as 103 days by executing the CPM-based repetitive scheduling procedure. Table IV also contains the probability values of completing within 103 days according to the simulated CPM-based repetitive scheduling procedure and RSRAM applications. Through these values, it can be observed that relying on the result obtained by the CPM-based repetitive scheduling procedure and not considering the riskfactors and their uncertainty creating effect on activity durations would give rise to wrong managerial decisions.

\section{B. Conducting Project-Risk Sensitivity Analysis}

In this section, the sensitivity of the project schedule to the risk factors is investigated. Knowledge of which risk factors are more effective for the project gives the manager the opportunity to manage the schedule better; knowing what to keep under control when managing the project prevents overrunning the planned schedule time. Controlling only the controlling activities is not sufficient for decreasing the risk of overrunning the schedule because the uncritical activities may also become critical due to the uncertainty in activity durations. For this reason, it is important to know what to control when managing both critical and uncritical activities. In this context, RSRAM has been designed with the capability of detecting which risk factors are more responsible for the uncertainty in the project. Table $\mathrm{V}$ contains the results of the project risk sensitivity analysis. When the table is examined, it is observed that risk factor 5 (labor productivity) creates the greatest variance, standard deviation, coefficient of variation, and maximum-minimum duration interval. This 
TABLE II

INPUT DATA OF RSRAM APPLICATION (PART 1)

\begin{tabular}{|c|c|c|c|c|c|c|}
\hline $\begin{array}{l}\text { Activity } \\
\text { Label }\end{array}$ & $\begin{array}{c}\text { Activity } \\
\text { Description }\end{array}$ & $\begin{array}{l}\text { Predecessor\& } \\
\text { Relationship }\end{array}$ & Unit1 & Unit2 & Unit3 & Unit4 \\
\hline & & & \multicolumn{4}{|c|}{$\begin{array}{c}\text { Duration in days } \\
\text { (minimum, most likely, maximum) }\end{array}$} \\
\hline A & Excavata & - & $(5,8,14)$ & $(5,8,14)$ & $(4,6,12)$ & $(4,6,12)$ \\
\hline $\mathrm{B}$ & Form slab & $\mathrm{A}(\mathrm{FS})$ & $(3,5,9)$ & $(3,5,9)$ & $(2,4,7)$ & $(2,4,7)$ \\
\hline $\mathrm{C}$ & Pour slab & $\mathrm{B}(\mathrm{FS})$ & $(3,4,8)$, & $(3,4,8)$, & $(2,3,6)$ & $(2,3,6)$ \\
\hline $\mathrm{D}$ & Frame exterior walls & $\mathrm{C}(\mathrm{FS}+3)$ & $(8,10,14)$ & $(8,10,14)$ & $(6,8,12)$ & $(6,8,12)$ \\
\hline $\mathrm{E}$ & Frame roof & $\mathrm{D}(\mathrm{FS})$ & $(4,6,10)$ & $(4,6,10)$ & $(3,4,8)$ & $(3,4,8)$ \\
\hline $\mathrm{F}$ & Brick sides & $\mathrm{D}(\mathrm{SS}+3)$ & $(9,12,16)$ & $(9,12,16)$ & $(7,10,14)$ & $(7,10,14)$ \\
\hline G & Rough electrical & $\mathrm{E}(\mathrm{FS}), \mathrm{F}(\mathrm{FS})$ & $(4,6,9)$ & $(4,6,9)$ & $(3,4,7)$ & $(3,4,7)$ \\
\hline $\mathrm{H}$ & Shingle roof & $\mathrm{E}(\mathrm{FS})$ & $(4,6,8)$ & $(4,6,8)$ & $(3,5,6)$ & $(3,5,6)$ \\
\hline $\mathrm{I}$ & Windows \& Doors & $\mathrm{F}(\mathrm{FF}+2)$ & $(5,8,12)$ & $(5,8,12)$ & $(4,6,10)$ & $(4,6,10)$ \\
\hline $\mathrm{J}$ & Insulate & $\mathrm{I}(\mathrm{FS}), \mathrm{G}(\mathrm{FS})$ & $(3,5,8)$, & $(3,5,8)$, & $(2,4,6)$ & $(2,4,6)$ \\
\hline $\mathrm{K}$ & Install drywall & $\mathrm{H}(\mathrm{FS}), \mathrm{J}(\mathrm{FS})$ & $(5,7,10)$ & $(5,7,10)$ & $(4,5,8)$ & $(4,5,8)$ \\
\hline $\mathrm{L}$ & Paint interior & $\mathrm{I}(\mathrm{FS}), \mathrm{K}(\mathrm{FS})$ & $(5,8,12)$ & $(5,8,12)$ & $(4,6,10)$ & $(4,6,10)$ \\
\hline $\mathrm{M}$ & Paint exterior & $\mathrm{F}(\mathrm{FS})$ & $(6,8,12)$ & $(6,8,12)$ & $(5,6,10)$ & $(5,6,10)$ \\
\hline $\mathrm{N}$ & Finish electrical & $\mathrm{M}(\mathrm{FS}), \mathrm{L}(\mathrm{FS})$ & $(2,4,6)$ & $(2,4,6)$ & $(2,3,5)$ & $(2,3,5)$ \\
\hline $\mathrm{O}$ & Close out & $\mathrm{N}(\mathrm{FS})$ & $(1,2,4)$ & $(1,2,4)$ & $(1,2,4)$ & $(1,2,4)$ \\
\hline
\end{tabular}

TABLE III

INPUT DATA OF RSRAM APPLICATION (PART 2)

\begin{tabular}{|c|c|c|c|c|c|c|c|c|c|c|c|}
\hline \multicolumn{2}{|c|}{ Risk-Factors } & $\begin{array}{c}1- \\
\text { Weather }\end{array}$ & $\begin{array}{c}2- \\
\text { Soil } \\
\text { conditions }\end{array}$ & $\begin{array}{c}3- \\
\text { Material } \\
\text { and } \\
\text { equipment } \\
\text { usage } \\
\text { efficiency }\end{array}$ & $\begin{array}{c}4- \\
\text { Design } \\
\text { sufficiency } \\
\text { and } \\
\text { design } \\
\text { changes }\end{array}$ & $\begin{array}{c}5- \\
\text { Labor } \\
\text { productivity }\end{array}$ & $\begin{array}{c}6- \\
\text { Subcontractor } \\
\text { productivity }\end{array}$ & $\begin{array}{c}7- \\
\text { Material } \\
\text { availability }\end{array}$ & $\begin{array}{c}\text { 8- } \\
\text { Disputes } \\
\text { with } \\
\text { owner }\end{array}$ & $\begin{array}{c}9- \\
\begin{array}{c}\text { Management } \\
\text { efficiency }\end{array}\end{array}$ & $\begin{array}{c}10- \\
\text { Activity } \\
\text { complexity }\end{array}$ \\
\hline \multirow{3}{*}{$\begin{array}{c}\text { Risk- } \\
\text { Factor } \\
\text { Situation } \\
\text { Probability } \\
\text { Boundaries }\end{array}$} & $\begin{array}{l}\text { better than } \\
\text { expected }\end{array}$ & 0.30 & 0.30 & 0.30 & 0.20 & 0.20 & 0.30 & 0.20 & 0.20 & 0.20 & 0.20 \\
\hline & expected & 0.70 & 0.70 & 0.60 & 0.70 & 0.60 & 0.60 & 0.80 & 0.60 & 0.60 & 0.70 \\
\hline & $\begin{array}{l}\text { worse than } \\
\text { expected }\end{array}$ & 1.00 & 1.00 & 1.00 & 1.00 & 1.00 & 1.00 & 1.00 & 1.00 & 1.00 & 1.00 \\
\hline
\end{tabular}

\begin{tabular}{|c|c|c|c|c|c|c|c|c|c|c|}
\hline \multirow{2}{*}{$\begin{array}{c}\begin{array}{c}\text { Activity } \\
\text { Label }\end{array} \\
\text { A }\end{array}$} & \multicolumn{10}{|c|}{ Activity Risk-Factor Influence Degrees } \\
\hline & $\begin{array}{c}\text { very } \\
\text { effective }\end{array}$ & $\begin{array}{c}\text { very } \\
\text { effective }\end{array}$ & effective & ineffective & effective & imeffective & imeffective & imeffective & effective & imeffective \\
\hline B & effective & ineffective & effective & ineffective & $\begin{array}{l}\text { very } \\
\text { effective }\end{array}$ & ineffective & ineffective & ineffective & effective & effective \\
\hline $\mathrm{C}$ & effective & ineffective & effective & ineffective & effective & ineffective & ineffective & ineffective & effective & ineffective \\
\hline D & effective & ineffective & $\begin{array}{c}\text { very } \\
\text { effective }\end{array}$ & effective & $\begin{array}{c}\text { very } \\
\text { effective }\end{array}$ & ineffective & ineffective & ineffective & effective & effective \\
\hline $\mathrm{E}$ & $\begin{array}{l}\text { very } \\
\text { effective }\end{array}$ & ineffective & effective & effective & $\begin{array}{c}\text { very } \\
\text { effective }\end{array}$ & ineffective & effective & ineffective & effective & effective \\
\hline F & effective & ineffective & effective & effective & $\begin{array}{c}\text { very } \\
\text { effective }\end{array}$ & ineffective & ineffective & ineffective & effective & effective \\
\hline $\mathrm{G}$ & ineffective & ineffective & effective & effective & effective & very effective & effective & ineffective & effective & effective \\
\hline $\mathrm{H}$ & $\begin{array}{c}\text { very } \\
\text { effective }\end{array}$ & ineffective & effective & ineffective & $\begin{array}{c}\text { very } \\
\text { effective }\end{array}$ & ineffective & effective & ineffective & effective & effective \\
\hline I & ineffective & ineffective & $\begin{array}{c}\text { very } \\
\text { effective }\end{array}$ & $\begin{array}{l}\text { very } \\
\text { effective }\end{array}$ & $\begin{array}{c}\text { very } \\
\text { effective }\end{array}$ & very effective & effective & effective & effective & $\begin{array}{l}\text { very } \\
\text { effective }\end{array}$ \\
\hline $\mathrm{J}$ & ineffective & ineffective & effective & effective & effective & ineffective & effective & effective & effective & $\begin{array}{l}\text { very } \\
\text { effective }\end{array}$ \\
\hline $\mathrm{K}$ & ineffective & ineffective & effective & effective & $\begin{array}{c}\text { very } \\
\text { effective }\end{array}$ & ineffective & effective & effective & effective & $\begin{array}{l}\text { very } \\
\text { effective }\end{array}$ \\
\hline L & ineffective & ineffective & $\begin{array}{l}\text { very } \\
\text { effective }\end{array}$ & effective & $\begin{array}{c}\text { very } \\
\text { effective }\end{array}$ & ineffective & effective & effective & effective & effective \\
\hline M & $\begin{array}{l}\text { very } \\
\text { effective }\end{array}$ & ineffective & $\begin{array}{l}\text { very } \\
\text { effective }\end{array}$ & effective & $\begin{array}{c}\text { very } \\
\text { effective }\end{array}$ & ineffective & effective & effective & effective & effective \\
\hline $\mathrm{N}$ & ineffective & ineffective & effective & effective & $\begin{array}{c}\text { very } \\
\text { effective }\end{array}$ & effective & effective & effective & effective & effective \\
\hline o & effective & ineffective & ineffective & ineffective & ineffective & ineffective & ineffective & $\begin{array}{l}\text { very } \\
\text { effective }\end{array}$ & effective & ineffective \\
\hline
\end{tabular}


TABLE IV

RESULTS OF SIMULATED CPM-BASED REPETITIVE SCHEDULING PROCEDURE AND RSRAM APPLICATIONS

\begin{tabular}{|c|c|c|c|c|c|c|c|c|c|c|}
\hline Method & & $\begin{array}{l}\text { Probability of } \\
\text { completing } \\
\text { within } 103 \\
\text { days, which is } \\
\text { the project } \\
\text { completion } \\
\text { duration } \\
\text { found by } \\
\text { CPM-based } \\
\text { repetitive } \\
\text { scheduling } \\
\text { procedure }\end{array}$ & $\begin{array}{l}\text { Minimum } \\
\text { Project } \\
\text { Duration } \\
\text { (day) }\end{array}$ & $\begin{array}{c}\text { Maximum } \\
\text { Project } \\
\text { Duration } \\
\text { (day) }\end{array}$ & $\begin{array}{c}\text { Mean } \\
\text { Project } \\
\text { Duration }\end{array}$ & $\begin{array}{c}\text { Standard } \\
\text { Deviation } \\
\text { of } \\
\text { Project } \\
\text { Duration } \\
\text { (day) }\end{array}$ & $\begin{array}{l}\text { Captured } \\
\text { correlation } \\
\text { coefficient } \\
\text { between } \\
\text { Activity A } \\
\text { - Activity } \\
\text { B } \\
\text { for Unit-1 }\end{array}$ & $\begin{array}{l}\text { Captured } \\
\text { correlation } \\
\text { coefficient } \\
\text { between } \\
\text { Activity C - } \\
\text { Activity D } \\
\text { for Unit-2 }\end{array}$ & $\begin{array}{l}\text { Captured } \\
\text { correlation } \\
\text { coefficient } \\
\text { between } \\
\text { Activity E } \\
\text { - Activity } \\
\text { F } \\
\text { for Unit-3 }\end{array}$ & $\begin{array}{l}\text { Captured } \\
\text { correlation } \\
\text { coefficient } \\
\text { between } \\
\text { Activity G } \\
\text { - Activity } \\
\text { H } \\
\text { for Unit-4 }\end{array}$ \\
\hline $\begin{array}{l}\text { Simulated } \\
\text { CPM-based } \\
\text { repetitive } \\
\text { construction } \\
\text { scheduling } \\
\text { procedure }\end{array}$ & 98.80 & $2.2 \%$ & & 129.71 & 113.33 & 5.18 & -0.009 & -0.064 & -0.009 & 0.022 \\
\hline RSRAM & 80.17 & $35.5 \%$ & & 148.04 & 107.73 & 9.89 & 0.69 & 0.93 & 0.89 & 0.92 \\
\hline
\end{tabular}

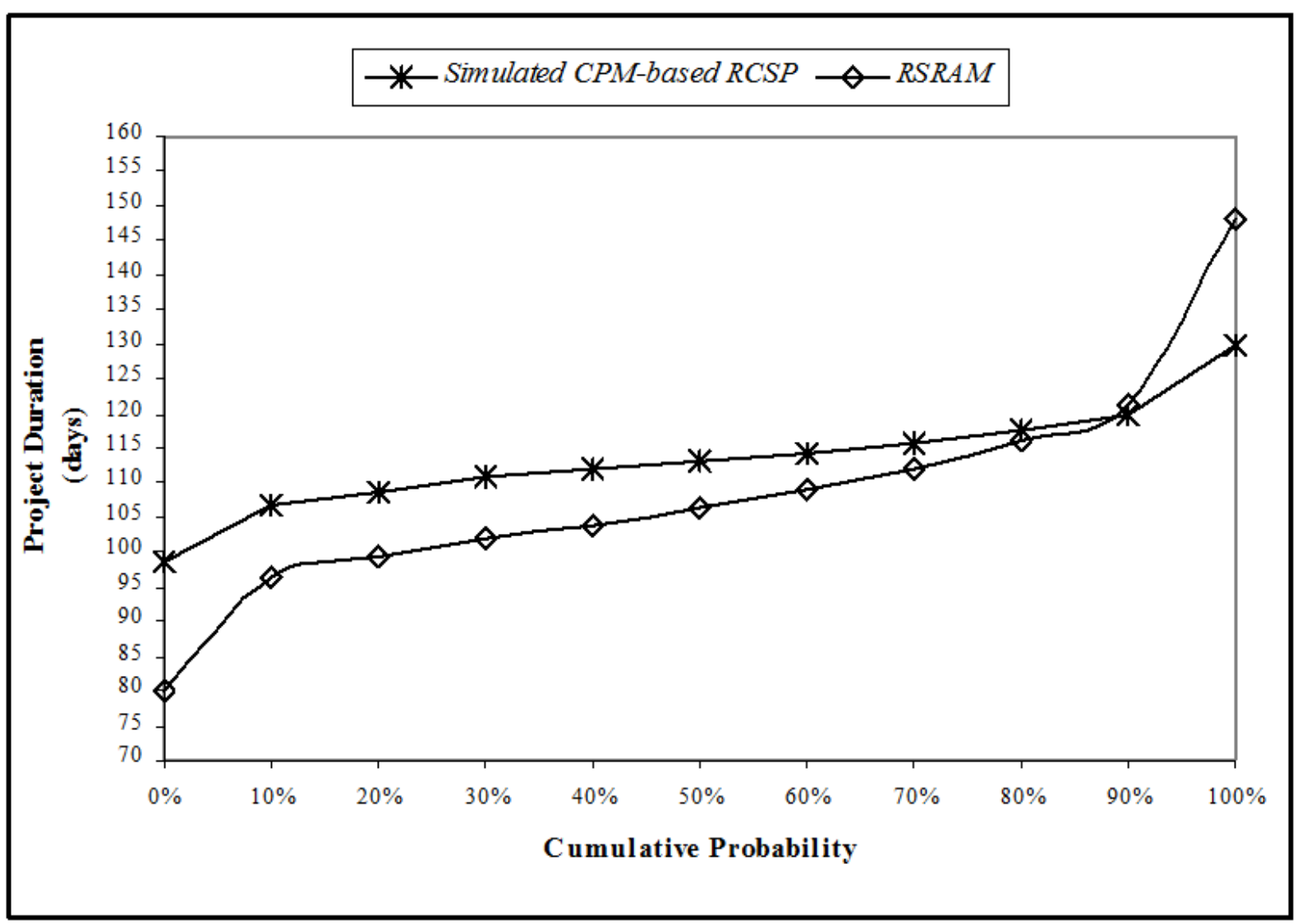

FIGURE IV

CUMULATIVE PROBABILITY DISTRIBUTIONS OF PROJECT DURATION IN SIMULATED CPM-BASED REPETITIVE SCHEDULING PROCEDURE AND RSRAM APPLICATIONS 
TABLE V

RESULTS OF PROJECT-RISK SENSITIVITY ANALYSIS

\begin{tabular}{lccccccc}
\hline \multicolumn{1}{c}{ Scenario } & $\begin{array}{c}\text { Minimum } \\
\text { Project } \\
\text { Duration } \\
\text { (day) }\end{array}$ & $\begin{array}{c}\text { Maximum } \\
\text { Project } \\
\text { Duration } \\
\text { (day) }\end{array}$ & $\begin{array}{c}\text { Mean } \\
\text { Project } \\
\text { Duration } \\
\text { (day) }\end{array}$ & $\begin{array}{c}\text { Variance } \\
\text { of } \\
\text { Project } \\
\text { Duration }\end{array}$ & $\begin{array}{c}\text { Standard } \\
\text { Deviation of } \\
\text { Project } \\
\text { Duration }\end{array}$ & $\begin{array}{c}\text { Coefficient of } \\
\text { Variation of } \\
\text { Project } \\
\text { Duration }\end{array}$ & $\begin{array}{c}\text { Sensitivity } \\
\text { Rank }\end{array}$ \\
\hline All Risk-Factors & 80.17 & 148.04 & 107.73 & 28.88 & 9.89 & 0.092 & - \\
Risk-Factor 1 & 98.10 & 112.26 & 103.76 & 10.67 & 3.27 & 0.032 & 2 \\
Risk-Factor 2 & 100.16 & 109.84 & 103.67 & 5.33 & 2.31 & 0.022 & 5 \\
Risk-Factor 3 & 98.01 & 111.18 & 103.92 & 10.85 & 3.29 & 0.032 & 3 \\
Risk-Factor 4 & 100.30 & 106.80 & 103.31 & 1.36 & 1.85 & 0.018 & 6 \\
Risk-Factor 5 & 95.73 & 114.51 & 104.46 & 18.43 & 4.29 & 0.041 & 1 \\
Risk-Factor 6 & 102.65 & 103.14 & 102.95 & 1.58 & 0.13 & 0.001 & 10 \\
Risk-Factor 7 & 102.02 & 104.51 & 103.05 & 0.19 & 0.44 & 0.004 & 9 \\
Risk-Factor 8 & 101.43 & 105.89 & 103.45 & 1.11 & 1.05 & 0.010 & 8 \\
Risk-Factor 9 & 98.56 & 110.31 & 103.99 & 7.49 & 2.74 & 0.026 & 4 \\
Risk-Factor 10 & 99.76 & 107.61 & 103.37 & 3.04 & 1.74 & 0.017 & 7 \\
Risk-Factor 1 2 & 95.27 & 119.09 & 104.47 & 30.07 & 5.48 & 0.052 & - \\
Risk-Factor 5 9 & 91.76 & 121.83 & 106.07 & 49.77 & 7.06 & 0.067 & - \\
\hline
\end{tabular}

means that risk factor 5 is the most responsible factor for the project duration variance, and in turn, is the factor most responsible for the schedule uncertainty. Sensitivity rank of the risk factors is also given in Table V. Risk factors have been ranked according to the coefficient of variation values. Furthermore, the other statistical values reveal that risk factors 1-2 (weather-soil conditions) and risk factors 5-9 (labor productivity-management efficiency), which are correlated in between, are the most effective risks when they are considered correlated in the sensitivity analysis. Thus it is important to focus on these risk factors during the management of the project in order to lower the uncertainty effect and in turn to lower the risk of overrunning the planned project completion time. However, the risk factors that are more effective (especially for the uncritical units, which are candidates for turning to critical due to the uncertainty effect) should also be known in order to manage the project properly and decrease the uncertainty effect.

\section{LIMITATIONS OF RSRAM}

The limitations of RSRAM can be described as follows:

- Dependence on realistic input data: In order to get realistic results from RSRAM, the data entered in the model should be realistic. First of all, work breakdown structure and network relationships between activities should cover the schedule requirements. Next, minimum, maximum and most likely activity unit durations should be determined realistically by taking the project conditions, resources and constraints into consideration. Finally; all of the "risk-factors", "activity - risk factor influence degrees" and "risk-factor situation probability boundaries" should be determined properly by using appropriate risk identification techniques. Obviously, unrealistic or missing input data would produce unrealistic and wrong results.

- Default model parameters: Activity - risk factor influence degrees are entered as very-effective, effective or ineffective qualitative terms. However, one may argue about very-very-effective term or very-very-very effective term. There is no limit for this. However, the amount of input data would increase as the number of such terms is increased. A model, to claim practicality, should require simplified input data as much as possible.

- The CPM-based repetitive construction scheduling procedure used in the model assumes the number of repetitive units constant through all activities and it uses the same group of activities for each unit. However, some units may not contain some of the activities the other units commonly include. Elimination of this limitation would improve RSRAM.

- The CPM-based repetitive construction scheduling procedure used in the model assumes single crew per activity. This is not practical for repetitive projects. It can be improved further by considering multiple crew usage and resource availability constraints.

\section{CONCLUSIONS AND FUTURE WORK}

In this study, a new schedule risk analysis model called RSRAM has been introduced. RSRAM is a simulationbased model developed for the purpose of evaluating unitbased repetitive building schedules under uncertainty when activity durations and risk factors are correlated. The proposed model utilizes Monte Carlo Simulation and a 
Critical Path Method based repetitive scheduling procedure. This new procedure concurrently provides the utilization of resources without interruption and the maintenance of network logic through successive units. Furthermore, it enables assigning variable production rates to the activities from one unit to another and any kind of relationship type with or without lag time.

The paper includes the operational logic of the RSRAM and its application on a multi-unit warehouse building project. Furthermore, foreseen limitations of the model have been emphasized. The results of the example application show that RSRAM operates well and produces realistic results regarding the uncertainty extent inherent in the schedule. However, RSRAM should be further tested on several repetitive type schedules. Different case studies are being carried out for this purpose; this paper comprises only the development of the model. RSRAM can be computerized easily by utilizing table processor software and embedded macros and can be further designed in a user-friendly form. In this paper, MS Excel and @Risk software programs have been used for RSRAM's execution.

\section{REFERENCES}

[1] O. Moselhi, A. Hassanein, "Optimized Scheduling of Linear Projects", Journal of Construction Engineering and Management, vol. 129, no. 6, pp. 664-673, 2003.

[2] K. El-Rayes, O. Moselhi, "Resource-driven scheduling of repetitive projects", Journal of Construction Management and Economics, vol. 16, pp. 433-446, 1998.

[3] D.B. Ashley, "Simulation of repetitive-unit construction", ASCE Journal of Construction Division, vol. 106, no. 2, pp. 185-194, 1980.

[4] S. Selinger, "Construction planning for linear projects", ASCE Journal of Construction Division, vol. 106, no. 2, pp. 195-205, 1980.

[5] RM. Reda, "RPM: Repetitive project modeling", Journal of Construction Engineering and Management, vol. 116, no. 2, pp. 316-330, 1990.

[6] A.D. Russell, W.C.M. Wong, "New generation of planning structures", Journal of Construction Engineering and Management, vol. 119, no. 2, pp. 196-214, 1993.

[7] T. Hegazy, O. Moselhi, P.Fazio, "BAL: An algorithm for scheduling and control of linear projects", AACE Trans, C8-1-C8-14, 1993.

[8] D. Arditi, M.Z. Albulak, "Line-of-balance scheduling in pavement construction", Journal of Construction Engineering and Management, vol. 112, no. 3, pp. 411-424, 1986.

[9] P. Lumsden, "The line of balance method", London: Pergamon Press Ltd, 1968.

[10] J.J. O'Brien, "VPM scheduling for high-rise buildings", Journal of Construction Division, ASCE, vol. 101, no. 4, pp. 895-905, 1975.

[11] D.W. Johnston, "Linear scheduling method for highway construction", Journal of Construction Engineering and Management, vol. 107, no. 2, pp. 247-261, 1981.

[12] O. Stradal, J. Cacha, "Time space scheduling method", Journal of Construction Division, ASCE, vol. 108, no. 3, pp. 445-457, 1982.

[13] M.J. Mawdesley, "Time change charts for scheduling linear projects", Proceedings of the 6th ASCE Conference on Computing in Civil Engineering, pp. 613-620, 1989.

[14] M.A. Ammar, E. Elbeltagi, "Algorithm for determining controlling path considering resource continuity", Journal of Computing in Civil Engineering, vol. 15, no. 4, pp. 292-298, 2001.

[15] D.J. Harmelink, J.E. Rowings, "Linear scheduling model: Development of controlling activity path", Journal of Construction Engineering and Management, vol. 124, no. 4, pp. 263-268, 1998.

[16] K.G. Mattila, D.M. Abraham, "Resource leveling of linear schedules using integer linear programming", Journal of Construction Engineering and Management, vol. 124, no. 3, pp. 232-244, 1998.
[17] R.B. Harris, P.G. Ioannou, "Scheduling projects with repeating activities", Journal of Construction Engineering and Management, vol. 124, no. 4, pp. 269-273, 1998.

[18] G.A. Duffy, G.D. Oberlender, D.H.S. Jeong, "Linear scheduling model with varying production rates", Journal of Construction Engineering and Management, vol. 137, no. 8, pp. 574-582, 2011.

[19] K. Cho, T. Hong, C. Hyun, "Scheduling model for repetitive construction processes for high-rise buildings", Canadian Journal of Civil Engineering, vol. 38, no. 1, pp. 36-48, 2011.

[20] A. Jaafari, "Criticism of CPM for project planning analysis", Journal of Construction Engineering and Management, vol. 110, no. 2, pp. 222-223, 1984.

[21] R. Flanagan, G. Norman, "Risk management and construction", Cambridge: Backwell Scientific, 1993.

[22] L. Edwards, "Practical risk management in the construction industry", London: Thomas Telford, 1995.

[23] A. Öztaş, Ö. Ökmen, "Risk analysis in fixed-price design-build construction projects", Building and Environment, vol. 39, pp. 229237, 2004.

[24] N. Sadeghi, A.R. Fayek, W. Pedrycz, "Fuzzy Monte Carlo Simulation and Risk Assessment in Construction", Computer-Aided Civil and Infrastructure Engineering, vol.25, no. 4, pp. 238-252.

[25] Dept of the Navy. "PERT, program evaluation research task", Washington: Phase I Summary Rep., Special Projects Office, Bureau of Ordnance, 1958.

[26] A.H.S. Ang, A.A. Chaher, J. Abdelnour, "Analysis of activity networks under uncertainty", Journal of the Engineering Mechanics Devision, vol. 101, no. 4, pp. 373-387, 1975.

[27] C.F. Diaz, F.C. Hadipriono, "Nondeterministic networking methods", Journal of Construction Engineering and Management, vol. 119, no. 1, pp. 40-57, 1993.

[28] W.C. Wang, L.A. Demsetz, "Application example for evaluating networks considering correlation", Journal of Construction Engineering and Management, vol. 126, no. 6, pp. 467-474, 2000.

[29] W.C. Wang, L.A. Demsetz, "Model for evaluating networks under correlated uncertainty-NETCOR", Journal of Construction Engineering and Management, vol. 126, no. 6, pp. 458-466, 2000.

[30] R.I. Carr, "Simulation of construction project duration", Journal of Construction Division, ASCE, vol. 105, no. 2, pp. 117-128, 1979.

[31] J.C. Woolery, K.C. Crandall, "Stochastic network model for planning scheduling", Journal of Construction Engineering and Management, vol. 109, no. 3, pp. 342-354, 1983.

[32] H.N. Ahuja, V. Nandakumar, "Simulation model to forecast project completion time", Journal of Construction Engineering and Management, vol. 111, no. 4, pp. 325-342, 1985.

[33] R.E. Levitt, J.C. Kunz, "Using knowledge of construction and project management for automated schedule updating", Project Management Journal, vol. 16, no. 5, pp. 57-76, 1985.

[34] L.S. Riggs, "Risk Management in CPM Networks", ComputerAided Civil and Infrastructure Engineering, vol. 4, no. 3, pp. 229235, 1989.

[35] M. Ranasinghe, A.D. Russell, "Treatment of correlation for risk analysis of engineering projects", Civil Engineering Systems, vol. 9, pp.17-39, 1992.

[36] A. Touran, E.P. Wiser, "Monte Carlo technique with correlated random variables", Journal of Construction Engineering and Management, vol. 118, no. 2, pp. 258-272, 1992.

[37] A. Öztaş, Ö. Ökmen, "Judgmental risk analysis process development in construction projects", Building and Environment, vol. 40, no.9, pp. 1244-1254, 2005.

[38] I.T. Yang, "Risk Modeling of Dependence among Project Task Durations", Computer-Aided Civil and Infrastructure Engineering, vol. 22, no. 6, pp. 419-429, 2007.

[39] Ö. Ökmen, A. Öztaş, "Construction Project Network Evaluation with Correlated Schedule Risk Analysis Model (CSRAM)", Journal of Construction Engineering and Management, vol. 134, no. 1, pp. 49-63, 2008. 